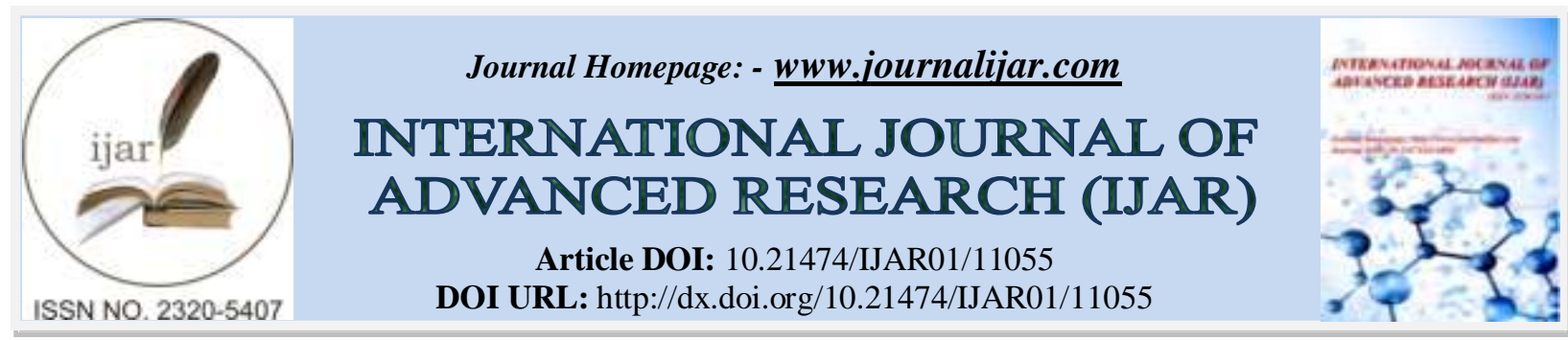

RESEARCH ARTICLE

\title{
EVALUATION OF THE EFFECT OF LOCAL ALCOHOLIC DRINKS IN GABON IN ADULT SUBJECTS
}

Hourfil-Gabin Ntougou Assoumou and Massande Wilfried

Ecole Normale Supérieure, Laboratoire le LASCIVIT, BP : 17009, LBV/ Gabon.

\section{Manuscript Info}

\section{Manuscript History}

Received: 25 March 2020

Final Accepted: 30 April 2020

Published: May 2020

Key words:-

Local Wine, Transaminases,

Alcoholism, GGT

\section{Abstract}

Background: The consumption of alcohol is part of the cultural diet, but its regular, excessive, or even abusive intake results in dysfunctions of several kinds. Among these alcohols, there are local alcohols that are highly appreciated and therefore excessive consumption has become a tradition. We also know that the metabolism of this product generates the production of metabolic markers, in this case, transaminases (aspartate aminotransferase (ASAT), alanine aminotransférase (ALAT) or gamma (GT) are indicators of toxicity.

Objectives: To assess the danger or toxicity of these alcohols, a crosssectional study was carried out. The aim of the study is to quantify and compare the serum values of transaminases (GGT, ASAT, ALAT) in different regular consumers of local alcohol in a population of Libreville. A cross-sectional observational survey on a sample of 116 people regardless of gender was carried out beforehand. Biological analyzes were carried out at the National Public Health Laboratory.

Material and Methods: Analysis of the results showed that local wines strongly influence the secretion of transaminases as GGT, ASAT, ALAT are 2 to 3 times higher compared to other alcohols and it shows how often this local wine is toxic for the organization. These results also show that almost $40 \%$ of people over the age of 50 indulge in the consumption of local drinks. This observation is supported by the attractiveness of the prices charged. These drinks would, therefore, be more accessible and within the reach of all budgets.

Conclusions: These results indicate that the excessive consumption of alcohol, regardless of their origin causes a high production of transaminases by the liver. These biomarkers are indicators of proven metabolic dysfunctions, more serious with age.

Copy Right, IJAR, 2020,. All rights reserved.

\section{Introduction:-}

Alcohol is an integral part of many cultures around the world, the number of people with excessive consumption of alcohol leading to alcohol dependence [1] is increasing sharply whether in Gabon or anywhere else. Indeed, in Gabon as elsewhere, there is a wide variety of artisanal alcohols which are widely consumed by the populations. This is a real public health problem, especially since the chemical composition of these different alcohols is unknown or even very approximate. It is also well known that excessive consumption of psychoactive substances is the second cause of morbidity and mortality after smoking [10,2]. 
In 2008, according to a survey by the World Health Organization (WHO), in Gabon the consumption of alcohol among individuals 15 years and over which was 9.5 liters per type of pure alcohol / person / year; and also another study conducted in Gabon by the STEPS survey in 2009 shows that the percentage of men consuming 5 or more drinks per day is $54.2 \%$ and that of women consuming 4 or more drinks is $39.9 \%$ [4].

Today in Libreville, the practices of daily consumption of local drinks vary; there are almost three times more men than women. This excessive consumption of products whose chemical nature is unknown is very dangerous, even suicidal. It is with this in mind that this descriptive study then proposes to assess the serum levels of transaminases, metabolic products and indicators of toxicity and other metabolic markers such as uric acid, urea, creatinine, and mean globular volume in adult subjects consuming local alcoholic beverages.

\section{Material And Methods:-}

\section{Setting of study:}

To carry out our study, the framework chosen was that of the National Public Health Laboratory (LNSP).

Study population

Patients from 4 districts of Libreville: Rio, Kinguélé, Avea 2 made up the study population. To be included, patients had to meet the following criteria: Inclusion criteria: - Be aged 18 and over; - Be a regular consumer of alcohol;

\section{Period and type of study:}

We carried out a cross-sectional observational survey over a period from March 16 to August 10, 2015.

\section{Ethical aspects and informed consent:}

Ethical aspects and informed consent were taken into account, above all respect for confidentiality in relation to the results of the study. In addition, the restitution of the results was effective for all participants of the study individually.

\section{Experimental protocol:}

This phase is characterized by filling in a questionnaire given to the volunteers followed by a blood sample.

The blood sample is taken by a venipuncture from a fasting subject. To achieve this we have needles of different calibers, micro tubes or Beckman tubes of $500 \mathrm{~mL}$ capacity, sterile disposable gloves, non-sterile cottons, a tourniquet and alcohol. After sampling, this tube is centrifuged at $3500 \mathrm{rpm}$ for $5 \mathrm{~min}$, the supernatant is used for the various examinations and the NFS tube is used directly.

\section{Biochemical assays:}

The determination of transaminases, gamma-GT, uric acid and VGM was carried out using Cobas C 111, Minday BS-380 and BC-3000 within the Biochemistry and Hematology departments of the National Public Health Laboratory de Libreville (LNSPL).

\section{Statistical analyzes:}

The data were entered into Excel (office 2010) and analyzed by Statview 5.0 software. The analyzes in the unpaired groups were carried out by the ANOVA tests. The Matrix test allowed the analysis of different correlations. A $p<$ 0.05 is considered statistically significant.

\section{Résultats:-}

For the present study, the population included 116 people (91 men out of 25 women) whose average age was 44.60 years (19 - 72 years).

Table I:- Distribution of consumers according to the type of wine consumed.

\begin{tabular}{|l|l|l|}
\hline Wine consumed & Population & Percentages \\
\hline Local wine & 47 & $40.51 \%$ \\
\hline Modern wine & 53 & $45.68 \%$ \\
\hline Wine Local/ modern & 16 & $13.79 \%$ \\
\hline Total & 116 & $100.00 \%$ \\
\hline
\end{tabular}


Consumers of modern drinks (45.68\%) are in the majority compared to the other two, although the differences have not been statistically evaluated.

Table II:- Variation in biological parameters depending on the wine consumed.

\begin{tabular}{|l|l|l|l|}
\hline Variables & Local wine $(\mathrm{n}=47)$ & Modern wine $(\mathrm{n}=53)$ & Local/Modern $(\mathrm{n}=16)$ \\
\hline GGT $(\mathrm{UI} / \mathrm{L})$ & $251.49 \pm 286.70^{*}$ & $75.95 \pm 84.14^{\mathrm{Y}^{*}}$ & $231.47 \pm 334.03$ \\
\hline ASAT $(\mathrm{UI} / \mathrm{L})$ & $86.00 \pm 73.28^{\mathrm{V}^{*}}$ & $37.51 \pm 21.18^{\mathrm{\gamma}^{*}}$ & $69.88 \pm 49.89$ \\
\hline ALAT $(\mathrm{UI} / \mathrm{L})$ & $55.60 \pm 59.72^{*}$ & $25.76 \pm 16.00^{* *}$ & $42.25 \pm 32.58$ \\
\hline Urée $(\mathrm{mmol} / \mathrm{L})$ & $2.91 \pm 1.21^{*}$ & $3.55 \pm 1.20^{*}$ & $3.82 \pm 2.90$ \\
\hline Creatinine $(\mu \mathrm{mol} / \mathrm{L})$ & $76.43 \pm 12.44$ & $76.17 \pm 14.85^{*}$ & $90.19 \pm 62.66$ \\
\hline AcUr $(\mu \mathrm{mol} / \mathrm{L})$ & $461.49 \pm 97.39^{\mathrm{y}^{*}}$ & $348.98 \pm 96.95^{\mathrm{\gamma}^{*}}$ & $405.26 \pm 115.48$ \\
\hline VGM $(\mathrm{fL})$ & $102.70 \pm 16.10^{*}$ & $95.87 \pm 8.92^{*}$ & $103.14 \pm 9.91$ \\
\hline
\end{tabular}

* $\mathrm{p}<0.05 ; * * \mathrm{p}<0.001$ and $\mathrm{\gamma} * \mathrm{p} \leq 0.0001$; GGT: $\mathrm{\gamma}$-glutamyl-transferase; ASAT: Aspartate Amino Transferase; ALAT: Alanine Amino Transferase; VGM: Average Globular Volume; AcUr: Uric acid. Local wine (Mussungu); Modern wine (Regab, Castel, Guinnesse, Beaufort etc.).

The results of Table II show that the consumption of local wines is accompanied by a massive increase in GGT, ASAT and ALAT are about 2 to 3 times higher than other alcohols. This increase is statistically significant $(p<0.0001)$. Unlike modern wine, which shows a significant increase $(p=0.0001)$ of about $1 / 3$ of the normal value. The consumption of the modern wine and local wine mixture induces an increase in GGT of more than 3 times greater than with modern wine but, curiously not significantly $(\mathrm{p}=0.26)$. It should be noted that there is a very large variability in the values of GGT and this makes this result difficult to exploit.

Table III:- Variation of transaminases, urea, creatinine, uric acid and blood volume according to age categories.

\begin{tabular}{|l|l|l|l|}
\hline \multirow{2}{*}{ Variables } & \multicolumn{3}{|c|}{ Age category } \\
\cline { 2 - 4 } & \multicolumn{1}{|c|}{$<30(\mathrm{n}=25)$} & $30-50(\mathrm{n}=47)$ & $>50(\mathrm{n}=44)$ \\
\hline GGT $(\mathrm{UI} / \mathrm{L})$ & $141.62 \pm 244.38^{*}$ & $174.27 \pm 184.96^{*}$ & $177.67 \pm 290.06$ \\
\hline ASAT $(\mathrm{UI} / \mathrm{L})$ & $57.64 \pm 74.88^{* *}$ & $64.94 \pm 48.95^{*}$ & $60.34 \pm 53.21$ \\
\hline ALAT $(\mathrm{UI} / \mathrm{L})$ & $41.440 \pm 73.36^{*}$ & $43.96 \pm 33.10^{*}$ & $35.27 \pm 28.20$ \\
\hline Urea $(\mathrm{mmol} / \mathrm{L})$ & $3.08 \pm 1.00^{*}$ & $3.43 \pm 1.20^{*} \mathrm{r}$ & $3.35 \pm 2.04$ \\
\hline Creatinine $(\mu \mathrm{mol} / \mathrm{L})$ & $75.24 \pm 20.80^{*}$ & $76.98 \pm 12.27^{* *}$ & $80.25 \pm 35.33$ \\
\hline AcUr $(\mu \mathrm{mol} / \mathrm{L})$ & $333.47 \pm 94.69^{*}$ & $393.88 \pm 90.69^{*}$ & $450.48 \pm 120.61$ \\
\hline VGM $(\mathrm{fL})$ & $91.91 \pm 9.45^{* *}$ & $99.72 \pm 10.76^{*} \mathrm{r}$ & $103.95 \pm 14.59$ \\
\hline
\end{tabular}

GGT: y-glutamyl-transferase, ASAT: Aspartate Amino Transferase; ALAT: Alanine Amino Transferase; VGM: Average Globular Volume; AcUr: Uric Acid.

Considering the age categories, slight modifications of the biological markers were obtained for this study as illustrated in Table III. The youngest ( $<30$ years) have lower values.

Table VI :- Shows the variation of transaminases, urea, creatinine, uric acid and blood volume as a function of the amount of drinks consumed per day.

\begin{tabular}{|l|l|l|l|}
\hline \multirow{2}{*}{ variables } & \multicolumn{3}{l|}{ Quantity of glasses per day } \\
\cline { 2 - 5 } & $\begin{array}{l}\text { Low }<7 \text { glasses } \\
(\mathrm{n}=27)\end{array}$ & $\begin{array}{l}\text { Mean } 7-12 \quad \text { glasses } \\
(\mathrm{n}=62)\end{array}$ & $>12$ glasses $(\mathrm{n}=26)$ \\
\hline GGT $(\mathrm{UI} / \mathrm{L})$ & $142.01 \pm 132.32$ & $152.42 \pm 228.58$ & $226.27 \pm 336.96$ \\
\hline ASAT $(\mathrm{UI} / \mathrm{L})$ & $54.52 \pm 38.43$ & $60.26 \pm 54.12$ & $68.89 \pm 74.82$ \\
\hline ALAT $(\mathrm{UI} / \mathrm{L})$ & $32.30 \pm 20.20$ & $42.02 \pm 51.86$ & $41.00 \pm 36.84$ \\
\hline Urea $(\mathrm{mmol} / \mathrm{L})$ & $3.52 \pm 1.59$ & $3.12 \pm 1.07$ & $3.64 \pm 2.25$ \\
\hline Creatinine $(\mu \mathrm{mol} / \mathrm{L})$ & $75.44 \pm 11.95$ & $77.65 \pm 14.78$ & $82.21 \pm 45.83$ \\
\hline AcUr $(\mu \mathrm{mol} / \mathrm{L})$ & $410.68 \pm 105.30$ & $402.12 \pm 119.47$ & $387.52 \pm 98.77$ \\
\hline VGM $(\mathrm{fL})$ & $103.43 \pm 17.30$ & $97.82 \pm 11.61$ & $99.05 \pm 8.12$ \\
\hline
\end{tabular}

GGT: y-glutamyl-transferase, ASAT: Aspartate Amino Transferase; ALAT: Alanine Amino Transferase; VGM: Average Globular Volume; AcUr: Uric Acid. 
The average concentrations of GGTs in subjects with risky consumption are higher than those in harmless consumption. No statistical cause and effect relationship between the elevation of GGT or any other biological marker and the number of drinks consumed during the day has been shown.

Table V:- Correlation matrix of biological markers.

\begin{tabular}{|c|c|c|c|c|c|c|c|}
\hline $\begin{array}{l}\text { Variables } \\
\text { Variables }\end{array}$ & $\begin{array}{l}\text { GGT } \\
\text { (U/L) }\end{array}$ & $\begin{array}{l}\text { ASAT } \\
\text { (UI/L) }\end{array}$ & $\begin{array}{l}\text { ALAT } \\
\text { (UI/L) }\end{array}$ & $\begin{array}{l}\text { Urée } \\
(\mathrm{mmol} / \mathrm{L})\end{array}$ & $\begin{array}{l}\text { Créat } \\
(\mu \mathrm{mol} / \mathrm{L})\end{array}$ & $\begin{array}{l}\text { AcUr } \\
(\mu \mathrm{mol} / \mathrm{L})\end{array}$ & VGM (fL) \\
\hline GGT (U/L) & 1 & $\begin{array}{l}0.672 \\
(<0.0001)\end{array}$ & $\begin{array}{l}0.531 \\
(<0.0001)\end{array}$ & $\begin{array}{l}-0.195 \\
(0.0535)\end{array}$ & -0.119 & 0.111 & $0.315(0.001)$ \\
\hline ASAT (UI/L) & & 1 & $\begin{array}{l}0.813 \\
(<0.0001)\end{array}$ & $\begin{array}{l}-0.285 \\
(0.0041) \\
\end{array}$ & -0.151 & 0.155 & 0.190 \\
\hline ALAT (UI/L) & & & 1 & $\begin{array}{l}- \\
0.241(0.0159)\end{array}$ & -0.118 & $\begin{array}{l}0.211 \\
(0.03) \\
\end{array}$ & 0.184 \\
\hline $\begin{array}{l}\text { Urea } \\
(\mathrm{mmol} / \mathrm{L})\end{array}$ & & & & 1 & $\begin{array}{l}0.646 \\
(<0.0001)\end{array}$ & -0.094 & -0.090 \\
\hline $\begin{array}{l}\text { Créatinine } \\
(\mu \mathrm{mol} / \mathrm{L})\end{array}$ & & & & & 1 & $\begin{array}{l}0.203 \\
(0.04) \\
\end{array}$ & 0.001 \\
\hline $\begin{array}{l}\text { AcUr } \\
(\mu \mathrm{mol} / \mathrm{L})\end{array}$ & & & & & & 1 & $\begin{array}{l}0.483 \\
(<0.0001)\end{array}$ \\
\hline VGM (fL) & & & & & & & 1 \\
\hline
\end{tabular}

In Table V, the strongest correlation is that of the ASAT - ALAT duo $(r=0.813)$ with $p=0.0001$ which is very significant. Then we have the binomial GGT / ASAT which presents a correlation which is slightly high $(\mathrm{r}=0.672)$ and which is significant $(\mathrm{p}<0.0001)$.

Relationship between the average rate of GGT and those of VGM, ASAT and ALAT
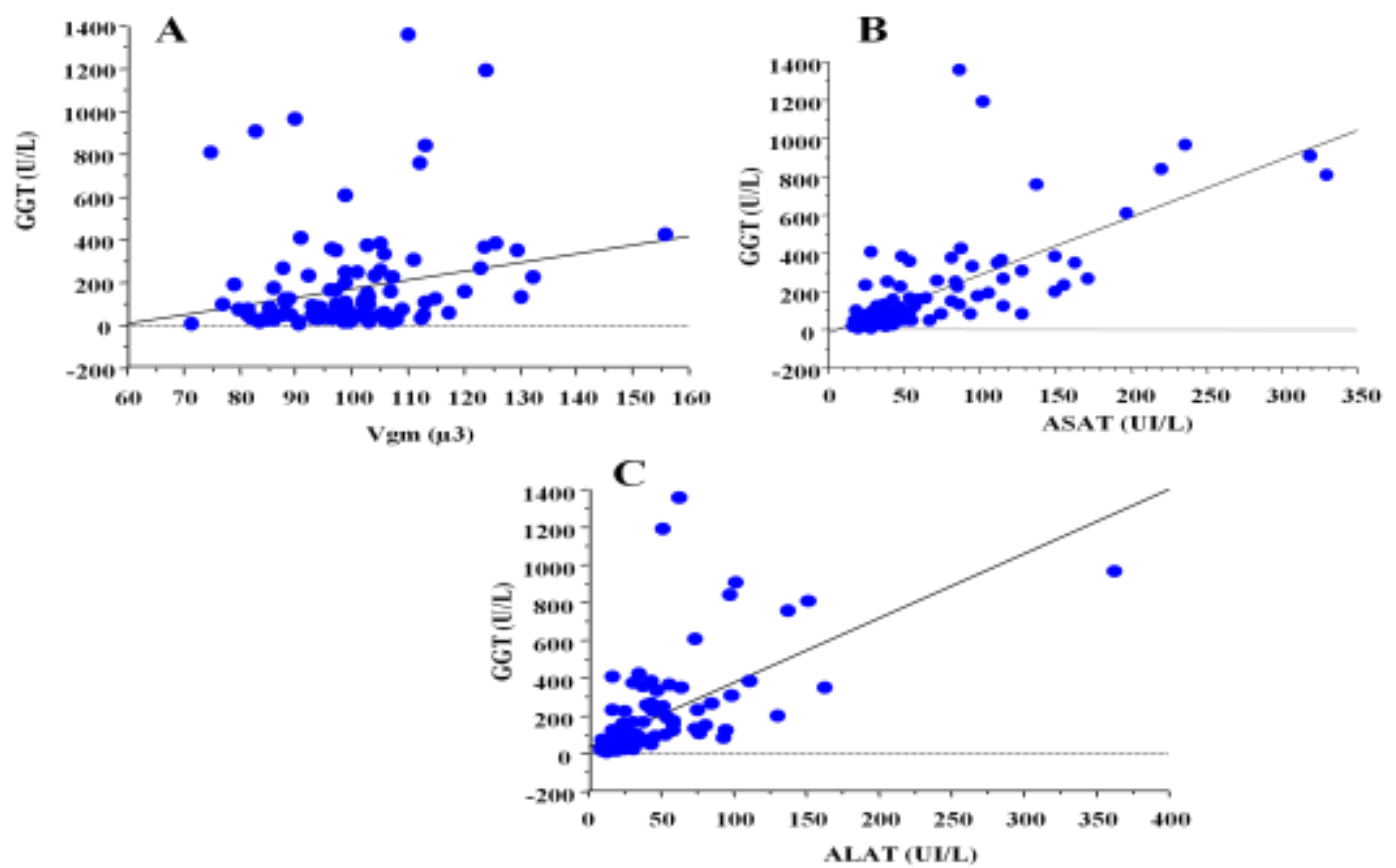

Figure 1:- Simple regression between the concentration of GGT and the other parameters, ASAT, ALAT and VGM In all the parameters examined, significant correlations were found between GGT and the other markers, by comparing their serum concentrations. This result is presented in Figure 1 ( $a, b$, and c for VGM, ASAT, ALAT respectively). This correlation was stronger for the GGT / ALAT duo. 


\section{Discussion:-}

Our results show that the assay of the various serum markers carried out in subjects consuming local alcoholic beverages is very revealing. Indeed, considerable changes in the serum levels of GGT, ASAT, ALAT and VGM have been observed among consumers of local wines in Gabon. However, from a general point of view, observations on the modifications of serum markers as a function of alcoholic drinks have already been observed elsewhere $[1,3]$.

The preferential trend suggests that consumers prefer this or that type of unmixed wine. The specificity of the unique taste of the wine can be highlighted from these observations. The average value of GGT, ASAT and ALAT was 2 to 3 times higher compared to modern wine among local wine consumers. This shows that the consumption of local wine creates a great release of this enzyme in the bloodstream. All this toxicity will therefore jeopardize the proper functioning of the liver, among others. What constitutes a potential risk of metabolic dysfunction.

Indeed, the production of local wine is not controlled and no standard in the matter exists. The production line run by a person with no idea of hygiene is therefore prone to infestations. The very origin of the distilled products is doubtful, because the distillation is done at an uncontrolled temperature and therefore disrespectful of the sterilization rules. The distillation time is either extended or insufficient. According to our results, all this would imply a production of rather toxic wines. In addition, after production, the transport and storage conditions contribute to an additional toxicity of this local wine. Neither sellers nor consumers know his alcohol level. Analysis of GGT levels among modern wine consumers suggests that this wine is less toxic than local wine. In this case, the frequency and quantity of consumption would be the only factors of its toxicity in chronic alcoholic subjects.

The other parameters ASAT and ALAT obey the same rules of toxicity, but with a moderate degree of toxicity $(\mathrm{p}=$ 0.0001 and $\mathrm{p}<0.001$ respectively for ASAT and ALAT). This is explained by the fact that transaminases are only released considerably in cases of severe conditions ranging from inflammatory syndrome to hepatocyte necrosis $[8,9]$.

The consumption of alcohol increases diuresis which is a defense reaction of the body hoping to decrease the level of alcohol in circulation, which leads to a dehydration in chronic subjects requiring compensation in water consumption. The VGM and uric acid are slightly modified with probabilities of $p<0.05$ and $p=0.0001$ because of the diuretic effect induced by excessive alcohol consumption, modifying the osmotic pressure of circulating liver cells . This increase in blood sugar levels due to alcohol is not only related to the amounts ingested, but also to the types of alcoholic beverages involved [4].

The data on the distribution of types of wine consumed are still poorly known, while according to this study the distribution is made for several reasons according to the average consumer.

According to some studies in General Medicine, the variation of GGT in men is influenced mainly by the importance of alcohol consumption and that of women is more influenced by the number of drinks consumed per day than by the number of days of consumption [5].

Comparing the variation in markers and age categories, it was noted that in the category of subjects over the age of 50 , the toxic effect of alcohol is much more pronounced $[3,4]$.

This elevation of parameters may be due to the incidence of the weight of the age, that is to say that the cells of the liver lose their specific functionalities. However, in subjects under the age of 30 , the toxic effect is less because their liver is able to effectively withstand the toxic effect of alcohol [7,9].

On the other hand, a study carried out on a group of people aged 21 to 35 shows a rate of $8 \%$ for GGT. This observation has been confirmed in other studies that GGTs are rarely elevated in people under the age of 30 [1].

Using the combination of the number of drinks consumed per day and the markers in 116 subjects with the inclusion criteria, it emerges from our study that 26 people are considered to be at risk consumers, since the number of drinks per day is greater than 12 . This observation is due to the importance of daily alcohol consumption and this seems to be fundamental to act on the serum level of biological markers $[1,4]$. 
We can say that those who consume more than 12 glasses per day have a tendency to eliminate their uric acid level than those who consume less than 7 glasses. Therefore, the diuretic effect or frequency of urine is greater in these people $[5,10]$.

In sum, the different correlations observed between certain parameters assume that there are associations between these different parameters which act in concert at the level of the organism to induce major dysfunctions with the example of ASAT and ALAT [5,6].

\section{Conclusions:-}

When evaluating alcohol markers in adult subjects consuming local alcoholic beverages, variations in the serum levels of these parameters were observed. In all contexts, the excessive consumption of alcohol is dangerous for health and is currently a public health problem (regardless of age, gender, geographic region). Compared to our study, the results support certain observations concerning the production of alcohol markers by the liver during excessive alcohol consumption. They also reveal the toxicity of these local drinks which is due to a nonformalization of the manufacturing and storage process, because at Libreville level the whole population is not sufficiently informed at all of the harmful consequences of these drinks in the body. And finally they reveal the existence of a strong correlation between these markers which may be due to the alteration of the membrane of the liver cells.

\section{Aknwoledgments:-}

The authors of this article declare that they have no conflict of interest of any form. We are very grateful to Professor ONDO Joseph Privat for his precious contribution.

\section{References:-}

1. Saunders JB, Aasland OG, Babor TF, de la Fuente JR, Grant M. Development of the Alcohol Use Disorders Identification Test (AUDIT): WHO Collaborative Project on Early Detection of Persons with Harmful Alcohol Consumption--II. Addiction. 1993 Jun; 88(6):791-804. doi: 10.1111/j.1360-0443.1993.tb02093.x.

2. Bœuf-Cazou O1, Lapeyre-Mestre M, Niezborala M, Montastruc JL. Profile of psychoactive substances consumption in workplace. Therapie. 2011 Mar-Apr; 66(2):155-65. Epub 2011 Jun 6.

3. Deborah B, James L, Sandra F. Excessive alcohol use by non-elite sportsmen. Drug and Alcohol Review 18 (2), 201-205.

4. Nubukpo P1, Laot L, Clément JP. Addictive behaviors in the aged. Geriatr Psychol Neuropsychiatr Vieil. 2012 Sep; 10(3):315-24.

5. Whitfield JB, Hensley WJ, Bryden D, Gallagher H. Effects of age and sex on biochemical responses to drinking habits. Med J Aust. 1978 Dec 30; 2(14):629-32.

6. Meerkerk GJ1, Njoo KH, Bongers IM, Trienekens P, van Oers JA. Comparing the diagnostic accuracy of carbohydrate-deficient transferrin, gamma-glutamyltransferase, and mean cell volume in a general practice population. Alcohol Clin Exp Res. 1999 Jun; 23(6):1052-9.

7. De Sio S, Tittarelli R, Di Martino G, Buomprisco G, Perri R, Bruno G, Pantano F, Mannocchi G, Marinelli E, Cedrone F. Alcohol consumption and employment: a cross-sectional study of office workers and unemployed people. PeerJ. 2020 Mar 24; 8:e8774.

8. Voon V, Grodin E, Mandali A, Morris L, Doñamayor N, Weidacker K, Kwako L, Goldman D, Koob GF, Momenan R. Addictions NeuroImaging Assessment (ANIA): Towards an integrative framework for alcohol use disorder. Neurosci Biobehav Rev. 2020 Apr 13;113:492-506.

9. Rosoff DB, Charlet K, Jung J, Lee J, Muench C, Luo A, Longley M, Lohoff FW. Lipid profile dysregulation predicts alcohol withdrawal symptom severity in individuals with alcohol use disorder. Alcohol. 2020 Apr 23. pii: S0741-8329(20)30178-6.

10. Laraqui O, Laraqui S, Manar N, Ghailan T, Deschamps F, Laraqui CH1. Prevalence of consumption of addictive substances amongst Moroccan fishermen. Int Marit Health. 2017; 68(1):19-25. 